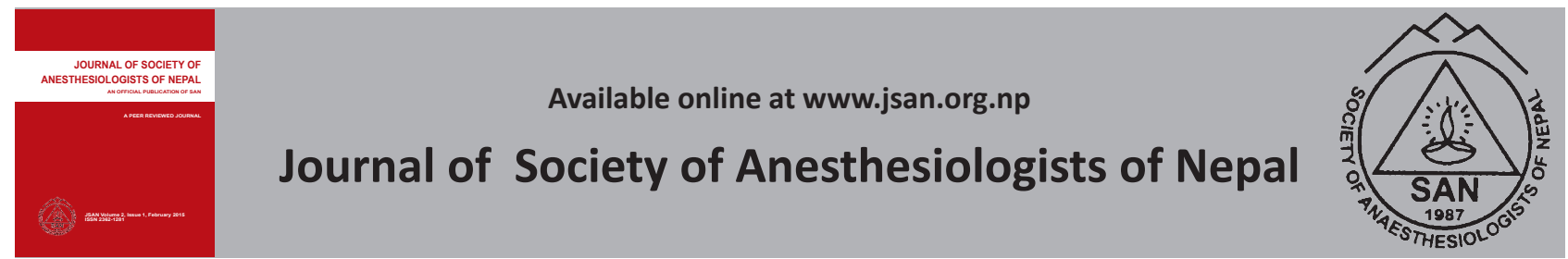

Original Article

\title{
Hemodynamic response to Sevoflurane and Propofol induction: a comparative study
}

Prabhat Rawal, * Uday Bajracharya**

*Nepal Armed Police Force Hospital, Balambu, Kathmandu, Nepal.

*Shree Birendra Military Hospital, Chhauni.

A R T I C L E I N F O
Article history
Received 20.08 .2014
Accepted 07.01 .2015
Published 26.02 .2015
C Authors retain copyright
and grant the journal right
of first publication with the
work simultaneously licensed
under a Creative Commons
Attribution License that allows
others to share the work with
an acknowledgment of the
work's authorship and initial
publication in this journal.

How to cite this article: Rawal P, Bajracharya U. Hemodynamic response to Sevoflurane and Propofol induction: a comparative study. JSAN 2015;2:2-7.

Corresponding author:

Prabhat Rawal, MD

Anesthesiologist, Department of Anesthesiology, Nepal Armed Police Force Hospital,

Balambu, Kathmandu, Nepal.

Phone: +9779803712083

Email: prabhat.rawal@gmail.com

\begin{abstract}
Background: Induction of anesthesia is a critical event and hemodynamic stability is an important factor during this period. Propofol is a commonly used intravenous anesthetic and Sevoflurane is a newly introduced inhalational anesthetic in the context of a developing country. This study compared the hemodynamics on induction of anesthesia with Propofol and Sevoflurane.
\end{abstract}

Methods: A total of 108 American Society of Anesthesiologists physical status I randomized into two groups. Group ' $P$ ' patients were induced with intravenous 1\% Propofol and Group ' $\mathrm{S}$ ' patients were induced with inhalation of $8 \%$ Sevoflurane. Mean arterial pressures and heart rates were recorded at baseline, before induction, during induction and at 1, 3 and 5 minutes after induction of anesthesia before endotracheal intubation.

Results: The two groups were comparable with respect to demographics and baseline hemodynamic parameters. There was a significant decrease in mean arterial pressure and heart rate from pre-induction values within both groups during and after induction. The reduction in mean arterial pressure was significantly more in Propofol group transiently during induction. The reduction in heart rate was significantly more in Sevoflurane group at 1, 3 and 5 minutes after induction $(P<0.05)$.

Conclusion: Induction of anesthesia with Propofol demonstrated a greater decrease in mean arterial pressure whereas induction with Sevoflurane was associated with greater reduction in heart rate.

Keywords: Anesthesia; Hemodynamics; Propofol; Sevoflurane patients undergoing elective surgical procedures under general anesthesia were 


\section{Introduction}

Induction of anesthesia can be achieved either by inhalational or intravenous (IV) anesthetics. Propofol is a commonly used IV anesthetic with desirable properties of rapid induction and recovery. However, hypotension, injection pain and apnea are some of its adverse effects during induction of anesthesia. ${ }^{1}$ Sevoflurane is an ecofriendly inhalational anesthetic with rapid induction and recovery profile. It is non-irritant to the airway, a potent bronchodilator and relatively preserves spontaneous ventilation during anesthetic induction. ${ }^{2}$ It is also a relatively new anesthetic in the context of a developing country and this necessitates the study of its anesthetic properties on local population.

Anesthetic induction is a critical event and hemodynamic stability is an important component of smooth anesthetic induction. ${ }^{3}$ Most studies have shown Sevoflurane to have better hemodynamic stability as compared to Propofol during induction of anesthesia. ${ }^{4,5}$ Some others have shown similar cardiovascular profiles between them. ${ }^{6}$ The objective of this study was to compare the Mean Arterial Pressure and Heart Rate response to induction with Propofol and Sevoflurane in American Society of Anesthesiologists physical status I (ASA PS I) patients, not in the extremes of ages.

\section{Material and methods}

Approval was taken from the Institutional Review Board Ethics Committee before commencing the study. A written informed consent was taken from each patient who met the inclusion criteria, before enrollment into the study. This was a prospective, randomized, single-blind study. A total of 108 ASA I patients of either gender between 18 to 55 years of age undergoing elective surgery under general anesthesia with endotracheal intubation were included. Patients with a history of allergy to volatile anesthetics or Propofol, anticipated difficult mask ventilation, communication problems, baseline mean arterial pressure (MAP) less than $70 \mathrm{mmHg}$ and heart rate (HR) less than 60 beats per minute (bpm) were excluded from the study.

The patients were randomly allocated into two groups of 54 each, Group P or Propofol group and Group S or Sevoflurane group using the sealed envelope technique. The patients were kept nil per orally from midnight, the day before the surgery. In the operating room, patient monitors (Vismo bedside monitor, Model BSM-2301K; SNo: 2340, Mf: 2007, Nihon Kohden, Tokyo, Japan) including noninvasive blood pressure, electrocardiography, and pulseoximeter were attached. Baseline Mean Arterial Pressure (MAP) and Heart Rate (HR) were noted. After securing an IV line in a large forearm vein, Pethidine $(0.75 \mathrm{mg} / \mathrm{kg})$ was injected and Ringer Lactate was administered at the rate of $5 \mathrm{ml} / \mathrm{kg}$ over 15 minutes.

Group P patients were induced with titrating dose of $1 \%$ Propofol (10 mg/ml Propofol- ${ }^{\circledR}$ Lipuro) injected manually at the rate of $1.5 \mathrm{ml}$ every 5 seconds. Group $\mathrm{S}$ patients were induced with (8\%) Sevoflurane (Sevorane ${ }^{\circledR}$ ) at tidal breathing using circle system and Dräger Fabius ${ }^{\circledR}$ plus anesthesia machine (Ref: 8606800-14; SNo: ARZF0046; Dräger Medical AG \& Co. KG, Mf: 2008, Lübeck, Germany) with Dräger Vapor 2000 vaporizer. The circuit was primed with $8 \%$ Sevoflurane in oxygen at six litres per minute for 30 seconds. Face mask was then applied to obtain adequate seal. The patients were asked to breathe normally. The time of start of injection of propofol or mask placement with sevoflurane $8 \%$ was considered as 'starting point of induction'. The patients were asked every 5 seconds, to open the eyes and loss of response to this command was defined as loss of verbal contact. Eyelash reflex was then checked for additional confirmation of loss of consciousness which was defined as induction end point'. The time taken for anesthetic induction was recorded for both groups. Vecuronium $0.1 \mathrm{mg} / \mathrm{kg}$ was administered as muscle relaxant followed by gentle manual ventilation. For group $S$ patients, Sevoflurane was reduced to $4 \%$ and subsequently adjusted between 0.5 and $2 \%$ to maintain adequate depth of anesthesia clinically. For Group P patients, 10 to 20 mg increments were administered if the anesthetic depth was clinically judged to be inadequate (indicated by patient movement, swallowing, sweating, tachycardia, or MAP $>20 \%$ preinduction value). An additional dose of Pethidine 0.25 $\mathrm{mg} / \mathrm{kg}$ was permitted if deemed necessary. HR and MAP were recorded 2 minutes before induction (pre-induction), during induction and 1, 3 and 5 minutes after induction of anesthesia. Hemodynamic data collection was completed at this point. The patients were intubated 5 minutes after the administration of muscle relaxant. Anesthesia was maintained with oxygen, isoflurane, intermittent positive pressure ventilation and vecuronium and reversed with neostigmine $0.05 \mathrm{mg} / \mathrm{kg}$ and glycopyrrolate $0.01 \mathrm{mg} / \mathrm{kg}$. The patients were shifted to the post-operative ward after adequate recovery. When the patients were able to have a good conversation comfortably, they were subjectively enquired if there was any recall of unpleasant experience or awareness just before and during their sleep.

Complications during induction were recorded and managed accordingly. Apnea was managed with airway maneuvers to rule out obstruction, and if needed, supported with gentle manual ventilation. Hypotension was considered significant when MAP was less than $20 \%$ below pre-induction values and was managed by decreasing the delivery of anesthetic agents, administration of IV fluids and ephedrine $6 \mathrm{mg}$ dose increments when needed. Bradycardia ( $\mathrm{HR}<60 \mathrm{bpm}$ ), if associated with MAP or HR $<20 \%$ pre-induction values, was treated with atropine $0.6 \mathrm{mg}$. Tachycardia (HR $>20 \%$ pre-induction values) was managed by increasing the anesthetic depth and treatment of any other possible cause such as inadequate oxygenation, ventilation or analgesia. 


\section{Statistical analysis}

Sample size was calculated taking $\alpha$ error $=1.96(p<0.05)$ with $95 \%$ confidence Interval, Beta error $=1.282(90 \%$ power), based on MAP values from a previous study of similar nature by $V$ Priya et al. ${ }^{7} A$ total of 108 participants were required. Data entry and analysis was done using Statistical Package for the Social Sciences (SPSS) version 16.0. Independent samples T-test was applied to compare continuous variables (MAP, HR, age, weight, time taken for induction) between groups. Paired sample T-test was used for comparison of MAP and HR within each group. Pearson's Chi square test was used to analyze the comparability between the groups for categorical variables (male/female ratio). Analyzed data were presented as mean \pm standard deviation and percentage change for continuous variables and as numbers for categorical variables. $P$ value $<0.05$ was considered significant.

\section{Results}

A total of 108 patients (54 in each group) who met the inclusion criteria were enrolled in the study. None of the enrolled patients were excluded. The two groups were comparable with respect to demographics and baseline hemodynamic parameters.

Table 1: Demographic characteristics of the patient

\begin{tabular}{|c|c|c|c|}
\hline Variables & Propofol group $[P](n=54)$ & Sevoflurane group $[S](n=54)$ & Test of significance: $p$ value \\
\hline $\begin{array}{l}\text { Age [years] } \\
\text { (mean } \pm \text { SD) }\end{array}$ & $35.06 \pm 11.794$ & $35.78 \pm 10.719$ & 0.740 \\
\hline $\begin{array}{l}\text { Gender [Male } \\
\text { / Female] }\end{array}$ & $29 / 25$ & $19 / 35$ & 0.053 \\
\hline $\begin{array}{l}\text { Weight [kg] } \\
\text { (mean } \pm \text { SD) }\end{array}$ & $55.20 \pm 8.983$ & $58.06 \pm 9.527$ & 0.112 \\
\hline $\begin{array}{l}\text { Baseline MAP } \\
\text { (mean } \pm \text { SD) } \\
\mathrm{mmHg}\end{array}$ & $93.44 \pm 11.697$ & $97.7 \pm 12.207$ & 0.067 \\
\hline $\begin{array}{l}\text { Baseline HR } \\
\text { (mean } \pm \text { SD) } \\
\text { beats per } \\
\text { minute }\end{array}$ & $83.87 \pm 19.235$ & $88.13 \pm 19.286$ & 0.253 \\
\hline
\end{tabular}

$\mathrm{SD}=$ Standard Deviation; $\mathrm{n}=$ number of patients in each group

The pre-induction MAP and HR values were regarded as reference values for comparison of hemodynamic changes within the groups and there were no significant differences between them (Table 2 and 4). There was a significant decrease in MAP and HR within both the groups during and after anesthetic induction when compared with pre-induction values. However, the difference in MAP between the groups was significant only during induction, (table 2) where the reduction in MAP was greater in Group P as compared to Group S. On the other hand, the differences in HR between the groups were significant at 1,3 , and 5 minutes after induction of anesthesia where there was a greater reduction in Group $S$ as compared to Group P (Table 3).

Table 2: Comparison of Mean Arterial Pressure values between Group P and Group S

\begin{tabular}{lllc}
\hline Time & Propofol group [P](54) & Sevoflurane group [S] (54) & Test of significance $p$ value \\
\hline Pre-induction & $93.17 \pm 9.726$ & $94.04 \pm 10.742$ & 0.660 \\
During induction & $78.33 \pm 9.930$ & $82.93 \pm 10.918$ & $0.024^{*}$ \\
1 min after induction & $73.20 \pm 8.561$ & $74.87 \pm 10.042$ & 0.355 \\
3 min after induction & $70.17 \pm 7.457$ & $71.26 \pm 9.694$ & 0.513 \\
5 min after induction & $70.69 \pm 7.513$ & $72.44 \pm 8.840$ & 0.268 \\
\hline
\end{tabular}

Values are expressed as (mean $\pm \mathrm{SD}) \mathrm{mmHg} ;{ }^{*}=$ statistically significant 
Figure 1: Mean Arterial Pressure trends (mean values) at different time intervals

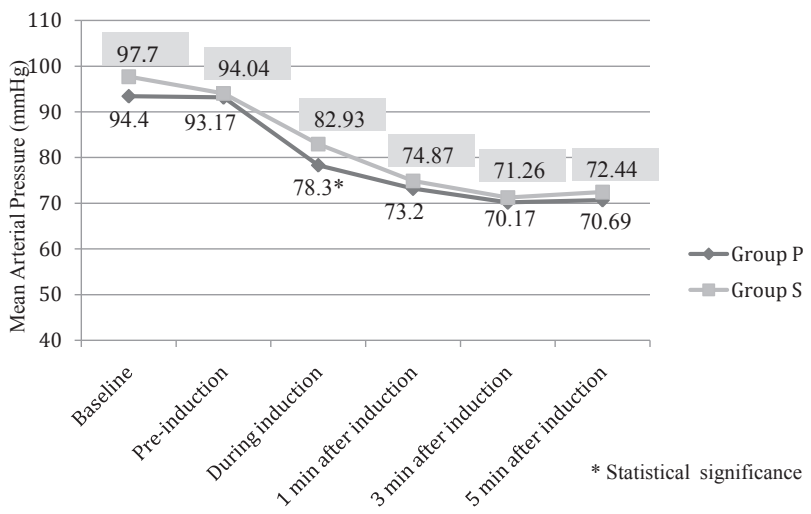

Figure 2: Heart rate trends (mean values) at different time intervals

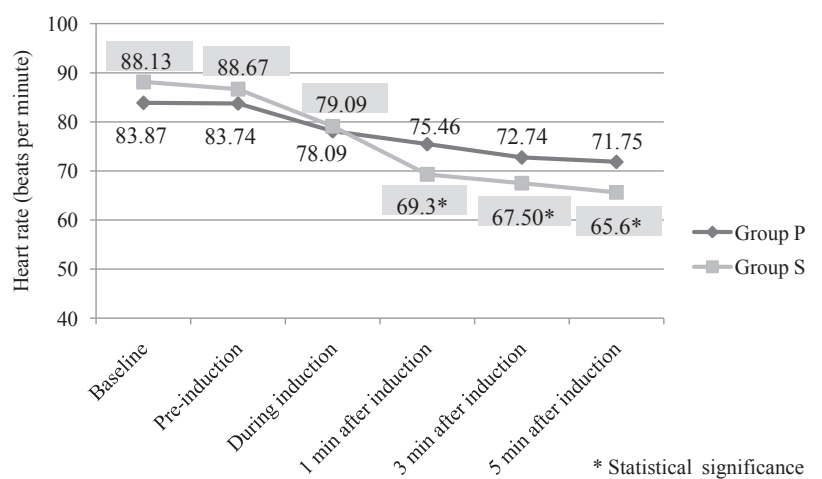

Table 3: Comparison of Heart rate values between Group P and Group S

\begin{tabular}{llll}
\hline Time & Propofol group [P] & Sevoflurane group [S] & Test of significance p value \\
\hline Pre-induction & $83.74 \pm 19.314$ & $86.67 \pm 20.635$ & 0.449 \\
During induction & $78.09 \pm 14.701$ & $79.09 \pm 14.741$ & 0.753 \\
1 min after induction & $75.46 \pm 15.200$ & $69.31 \pm 12.887$ & $0.025^{*}$ \\
3 min after induction & $72.74 \pm 14.492$ & $67.50 \pm 12.857$ & $0.049^{*}$ \\
5 min after induction & $71.85 \pm 14.760$ & $65.63 \pm 11.503$ & $0.016^{*}$
\end{tabular}

Values are expressed as (mean \pm SD) beats per minute; * = statistically significant

Hemodynamic adverse effects were defined and recorded as shown in Table 4. The incidence of hypotension and bradycardia (considering minimum values of MAP and HR attained for each patient) were not significantly different between Groups P and S. However, the incidence of HR less than $20 \%$ pre-induction value was significantly more in Group S as compared to Group P.

Table 4: Comparison of hemodynamic adverse effects between Group P and Group S

\begin{tabular}{llll}
\hline Adverse effects & Group P (54) & Group S (54) & p value \\
\hline Hypotension (MAP < 20\% pre-induction) & $44(81.48 \%)$ & $41(75.92 \%)$ & 0.481 \\
Bradycardia (HR $<60 \mathrm{bpm})$ & $15(27.77 \%)$ & $19(35.18 \%)$ & 0.407 \\
Heart rate $<20 \%$ pre-induction & $21(38.88 \%)$ & $32(59.26 \%)$ & $0.034 *$ \\
Tachycardia (HR $>20 \%$ pre-induction) & $3(5.55 \%)$ & $2(3.70 \%)$ & 0.647 \\
\hline
\end{tabular}

Values are expressed as number (percentage); ${ }^{*}=$ Statistically significant

The time taken for induction was significantly less $(\mathrm{p}=$ $0.000)$ for Sevoflurane group (45.31 \pm 10.097 seconds; mean \pm standard deviation) as compared to Propofol group (55.91 \pm 15.791 seconds). The mean dose of Propofol administered in Group P was $120.60 \pm 20.583 \mathrm{mg}(2.2$ $\mathrm{mg} / \mathrm{kg}$ ). None of the patients had any recall of unpleasant experience after the start of induction until full recovery from anesthesia.

\section{Discussion}

Inhalation induction is commonly performed in children but was largely a matter of history in adults until the introduction of Sevoflurane into clinical practice. Sevoflurane is an inhalational anesthetic having comparable properties to IV Propofol for anesthetic induction, maintenance and recovery. Inhalation induction is also preferred over intravenous induction in patients with anticipated difficult airway where spontaneous ventilation is preferred during induction. ${ }^{2}$ Sevoflurane was first synthesized in 1968 by Regan and colleagues at Baxter-Travenol laboratories, Illinois, USA. However, it was not used clinically because of concerns of potential nephrotoxicity due to its toxic metabolic end products, namely Compound A, fluoride ions and carbon monoxide. It was only two decades later that sevoflurane was introduced into clinical practice after adequate clinical trials without any apparent complications. ${ }^{8}$ Sevoflurane has thus, sparked renewed interest in inhalation induction in adults. ${ }^{9}$ 
Hemodynamic stability is an integral component of an ideal anesthetic induction. ${ }^{3}$ Although patients with cardiovascular diseases ${ }^{3}$ and elderly patients ${ }^{10}$ are more labile to hemodynamic changes during anesthetic induction, the associated risks cannot be overlooked in healthy candidates. Some authors have not found any hemodynamic differences between Sevoflurane and propofol whereas others favor one anesthetic over the other because of better hemodynamic stability. ${ }^{11}$ Mean Arterial Pressure values were specifically considered for analysis of blood pressure. MAP is the true driving pressure for peripheral blood flow and does not change as the pressure waveform moves distally, nor is it altered by distortions generated by recording systems. MAP was also found to be more accurately measured than systolic or diastolic blood pressure by non-invasive methods of blood pressure measurement such as oscillatory method. ${ }^{12}$

In this study, there was a decreasing trend of MAP in both the groups on induction of anesthesia with maximum decrease at 3 minutes after induction. A significant difference in MAP was observed between the two groups transiently during induction but not at 1, 3 and 5 minutes after induction of anesthesia. The first randomized, doubleblind comparison of an IV anesthetic with Sevoflurane was conducted by Thwaites, Emends and Smith in 1996. ${ }^{13}$ They observed a similar trend of decrease in MAP with both agents but significantly lower with Propofol at 2 to 5 min after induction of anesthesia as compared to $8 \%$ Sevoflurane. The use of Nitrous oxide $\left(\mathrm{N}_{2} \mathrm{O}\right)$ may have produced some of these minor differences in the timing and duration of hypotension, as compared to our study where $\mathrm{N}_{2} \mathrm{O}$ was not used. Smith and Thwaites ${ }^{14}$ in another study in 1999, using methods similar to ours, observed a significant difference in MAP, 1 minute after induction but not at other times, closely resembling our findings. Comparable results to ours were also obtained by Priya $V$ et $\mathrm{al}^{7}$ but the MAP difference was significant at 3 minutes after induction, possibly due to the administration of Fentanyl 2 $\mu \mathrm{g} / \mathrm{kg} \mathrm{IV}$, immediately after the induction end point. The Minimum Alveolar Concentration (MAC) equivalent of Sevoflurane to IV dose of Propofol for anesthetic induction is not known. ${ }^{13}$ Bharti $\mathrm{N}$ et $\mathrm{al}^{4}$ attempted to deliver comparable doses of Sevoflurane and Propofol by using a bispectral index (BIS) monitor to adjust similar anesthetic depths in both the groups. In their study, Propofol induction was associated with a greater decrease in MAP during induction as in our study. Similar findings have also been documented in pediatric ${ }^{15}$ and geriatric ${ }^{10}$ anesthesia. On the other hand, some authors have a different opinion. Konstantopoulos et $\mathrm{al}^{16}$ and Watson KR et al ${ }^{6}$ documented that MAP decreased progressively with both Sevoflurane and Propofol induction without any significant differences between them. However, the peri-induction recordings of MAP were relatively fewer in both these studies, perhaps, reducing their discriminatory value.
The hypotensive effect of Propofol has been attributed to a decrease in systemic vascular resistance or in cardiac output caused by a combination of venous and arterial vasodilation, impaired baroreflex mechanisms and depression of myocardial contractility. Sevoflurane, on the other hand causes mild cardiovascular depression by decreasing sympathetic nervous system activity. ${ }^{17}$

When heart rates were compared in our study, Sevoflurane group demonstrated a greater reduction than Propofol group at 1, 3 and 5 minutes after induction of anesthesia but not during induction. Thwaites, Emends and Smith ${ }^{13}$ in 1996, had found no significant differences in heart rate between Propofol and Sevoflurane induction. Contrary to our study, HR was observed to increase slightly after induction possibly because analgesics were not administered prior to induction and airway was managed by holding a face mask after induction without muscle relaxation. However, Smith and Thwaites ${ }^{14}$ in another study in 1999, demonstrated similar results to ours with a significant decrease in HR with sevoflurane at 3 and 5 minutes after induction. Priya $\mathrm{V}$ et $\mathrm{al}^{7}$ and Jellish WS et $\mathrm{al}^{8}$ et al observed a decrease in HR for both anesthetics up to several minutes after induction, but, in contrast to our study, the difference in HR between the two anesthetics was not statistically significant. Bharti $\mathrm{N}$ et $\mathrm{al}^{4}$, who monitored the induction depth of anesthesia using BIS, arrived at similar findings. In the latter three studies, the administration of Fentanyl $2 \mu \mathrm{g} / \mathrm{kg}$ IV, either just before or after induction could have attenuated the changes in HR.

Out of the various factors responsible for this variable $H R$ response, the most important determinant is probably the relation of the anesthetic depth with autonomic regulation of the cardiovascular system. This is called 'heart rate variability'. ${ }^{17,19}$ According to Kanaya $\mathrm{N}$ et $\mathrm{al}^{17}$, Propofol causes a decrease in peripheral sympathetic nerve activity and probably a decrease in cardiac parasympathetic activity. Hence, reduction in blood pressure may be observed despite an increase in HR. A decrease in HR may also be associated with Propofol induction due to direct negative chronotropic effect but not due to cardiac parasympathetic stimulation. On the other hand, Sevoflurane may inhibit sympathetic nervous activity without any significant changes in cardiac parasympathetic nerve activity. The baroreflex control of heart rate may also be inhibited. HR may not increase during hypotension. ${ }^{17}$ This might be responsible for the significantly greater decrease in heart rate observed with Sevoflurane induction than with Propofol induction as observed in our study.

The conduct of this study was limited by the availability of resources and technical feasibility in our experimental setup. Hemodynamic data could have been measured with greater accuracy and at more frequent intervals if invasive blood pressure monitoring had been used. A controlled infusion device should have been used to 
deliver Propofol. Sevoflurane concentration and Propofol dose administered would have been more comparable if an anesthetic depth monitor was available, along with an 'agent gas analyzer' for Sevoflurane and a target infusion level monitor for Propofol.

The differential effects of Sevoflurane and Propofol induction on hemodynamics in vivo may be more important in specific cardiovascular diseases and in elderly patients where it may be clinically appropriate to choose one anesthetic agent over the other. Adequate studies in specific cardiovascular disease conditions will be required to establish the clinical significance of these hemodynamic changes.

\section{Conclusion}

Induction of anesthesia with both Propofol and Sevoflurane was associated with a decreasing trend of mean arterial pressure and heart rate. However, the magnitude of this response was different because Propofol demonstrated a greater decrease in mean arterial pressure whereas Sevoflurane demonstrated a greater reduction in heart rate.

\section{Acknowledgements}

\section{References}

1. Ozkoçak I, Altunkaya H, Ozer $Y$, Ayoğlu H, Demirel CB, Ciçek E. Comparison of ephedrine and ketamine in prevention of injection pain and hypotension due to propofol induction. Eur J Anaesthesiol 2005;22:44-8.

2. Joshi GP. Inhalational techniques in ambulatory anesthesia Anesthesiology Clin N Am 2003;21:263-72.

3. Samad K, Khan F,Azam I. Hemodynamic effects of anesthetic induction in patients treated with beta and calcium channel blockers. M E J Anesth 2008;19:1111-28.

4. Bharti N, Chari P, Kumar P. Effect of Sevoflurane versus Propofo based anesthesia on the hemodynamic response and recovery characteristics in patients undergoing microlaryngeal surgery. Saudi J Anaesth 2012;6:380-4.

5. Zahoor MU, Mansoor R, Buland K, Kazi WA, UI Haq ME. Comparison of haemodynamic changes after laryngeal mask airway insertion with Propofol versus Sevoflurane. Pakistan Armed Forces Medical Journal 2010 Sept;(3).

6. Watson KR, Shah MV. Clinical comparison of 'single agent' anesthesia with Sevoflurane versus target controlled infusion of Propofol. Br J Anaesth 2000;85:541-6.

7. Priya V, Divatiya JV, Dasgupta D. A comparison of Propofol versus Sevoflurane for laryngeal mask airway insertion. Indian J Anaesth 2002;46:31-4
8. Katoh $\mathrm{T}$, Ikeda $\mathrm{K}$. The minimum alveolar concentration (MAC) of sevoflurane in humans. Anesthesiology 1987;66:301-3.

9. Van den Berg AA, Chitty DA, Jones RD, Sohel MS, Shahen A Intravenous or inhaled induction of anesthesia in adults? An audit of preoperative patient preferences. Anesth Analg 2005;100:14224.

10. 10. Kirkbride DA, Parker JL Williams GD, Buggy DJ. Induction of anesthesia in the elderly ambulatory patient: a doubleblinded comparison of Propofol and Sevoflurane. Anesth Analg 2001;93:1185-7.

11. Husedzinovic I, Tonkovic D, Barisin S, Bradic N, Gasparovic S. Hemodynamic differences in Sevoflurane versus Propofol anesthesia. Coll Antropol 2003;27:205-12.

12. Lakhal K, Macq C, Ehrmann S, Boulain T, Capdevila X. Noninvasive monitoring of blood pressure in the critically ill: reliability according to the cuff site (arm, thigh, or ankle). Crit Care Med 2012;40:120713

13. Thwaites A, Edmends S, Smith I. Inhalation induction with Sevoflurane: a double-blind comparison with Propofol. Br J Anaesth 1997;78:356-61.

14. Smith I, Thwaites AJ. Target-controlled Propofol vs. Sevoflurane: a double-blind, randomised comparison in day-case anaesthesia. Anaesthesia 1999;54:745-52.

15. Patel N, Patel MM, Patel V. Comparison of cardiovascular and respiratory changes during induction, maintenance and recovery with Sevoflurane and Propofol in pediatric day care anesthesia. Journal of Chemical and Pharmaceutical Research 2013;5:562-5.

16. Konstantopoulos K, Makris A, Moustaka A, Karmaniolou I, Konstantopoulos G, Mela A. Sevoflurane versus Propofol anesthesia in patients undergoing lumbar spondylodesis: a randomized trial. Journal of surgical research 2013;179:72-77.

17. Kanaya N, Hirata N, Kurosawa S, Nakayama M, Namiki A. Differential effects of Propofol and Sevoflurane on heart rate variability. Anesthesiology 2003;98:34-40.

18. Jellish WS, Lien CA, Fontenot HJ. The comparative effects of Sevoflurane versus Propofol in the induction and maintenance of anesthesia in adult patients. Anesth Analg 1996; 82:479-485.

19. Mäenpää M, Penttilä J, Laitio T, Kaisti K, Kuusela T, Hinkka S, et al. The effects of surgical levels of Sevoflurane and Propofol anesthesia on heart rate variability. Eur J Anaesthesiol 2007;24:626-33. 